\title{
ГЕРБЕРТ СПЕНСЕР - ЗАБЫТЫЙ ОТЕЦ ТЕОРИИ ДЕМОГРАФИЧЕСКОГО ПЕРЕХОДА
}

\author{
АНАТОЛИЙ ВИШНЕВСКИЙ
}

\begin{abstract}
Считается, что центральная идея современной теории демографического перехода как перехода от равновесия высоких к равновесию низких смертности и рождаемости была сформирована и стала общепризнанной в середине XX века. B статье показано, что эта идея была высказана и развита Гербертом Спенсером на сто лет раньше, хотя современные теоретики демографического перехода никогда не ссылаются на него как на своего предмественника.

Восстановление подлинной родословной теории демографического перехода - важная, но не единственная цель статьи. Ее главная задача привлечь аргументацию Спенсера к современным дебатам о настоящем и будущем низкой рождаемости, исходя из предпосылки, что эта аргументация не только не стала историческим раритетом, но и сегодня во многом опережает время. Главное внимание уделено различиям в понимании фундаментальных причин снижения рождаемости. В статье не отрииаются заблуждения Спенсера в понимании механизма снижения рождаемости в человеческом обществе, но что касается причин этого снижения, то, по мнению автора статьи, более высокий уровень обобщения, свойственный научному мировоззрению Спенсера, предопределил понимание этих причин, более глубокое, чем то, которое развивается современными демографами-теоретиками.
\end{abstract}

Ключевые слова: Спенсер, демографический переход, смертность, рождаемость, способность сохранять жизнь, антагонизм размножения и индивидуализации, закон сохранения видов, равновесие, причины снижения рождаемости, пронаталистская политика.

Как утверждал в конце XIX века известный итальянский ученый и государственный деятель Франческо Нитти, «заслуга создания широкой социологической доктрины о народонаселении принадлежит, прежде всего, Герберту Спенсеру; он первый выступил с учением, которое, хотя его и нельзя принять целиком, остается все же изумительным документом в истории теории народонаселения» [Нитти 1898: 95; Nitti 1894: 56-57].

Столь высокая оценка вклада Спенсера в теорию населения резко контрастирует с тем местом, которое отводят ему историки демографической мысли сегодня. В многотомном компендиуме по демографии, в главе, посвященной истории демографической мысли, из 65 страниц Спенсеру отведено менее 6 строк - среди других сторонников не стоящего серьезного рассмотрения «биологического подхода» [Vilquin 2006: 21].

Между тем взгляды Спенсера заслуживают гораздо большего внимания со стороны демографов - не как исторический реликт, а как круг идей, намного опередивших свое время и способных занять важное место в современной демографической теории. Это особенно справедливо, когда речь идет о теоретическом осмыслении едва ли не главной проблемы сегодняшней теоретической демографии - проблемы низкой рождаемости.

\footnotetext{
АНАТОЛИЙ ГРИГОРЬЕВИч ВИШНЕВСКИЙ (avishnevsky@hse.ru), НАЦИОНАЛЬНЫЙ ИССЛЕДОВАТЕЛЬСКИЙ УНИВЕРСИТЕТ «ВЫСШАЯ ШКОЛА ЭКОНОМИКИ», РОССИЯ.

В СТАТЬЕ ИСПОЛЬЗОВАНЫ РЕЗУЛЬТАТЫ ИССЛЕДОВАНИЙ, ВЫПОЛНЯВШИХСЯ В РАМКАХ ПРОГРАММЫ ФУНДАМЕНТАЛЬНЫХ ИССЛЕДОВАНИЙ НИУ ВШЭ в 2017-2018 ГГ.

СТАТЬЯ ПОСТУПИЛА В РЕДАКЦИЮ В ФЕВРАЛЕ 2019 Г.
} 
Спенсер заметил однажды, что «если мы желаем составить себе верную оценку какой-нибудь идеи, верную, по крайней мере, в главных чертах, то довольно надежным мерилом для этого может служить родословная этой идеи» [Спенсер 1999, т. 1: 113; Spencer 1891a: 108]. Основной объяснительной конструкцией, на которую опирается научная интерпретация современных демографических процессов, давно уже стала теория «демографической революции» или «демографического перехода». Она тоже имеет свою родословную, и, как я попытаюсь показать в этой статье, взгляды Спенсера - ее немаловажная, но, к сожалению, недооцененная часть.

Концепция демографического перехода выросла, прежде всего, из стремления осмыслить природу низкой рождаемости - относительно нового феномена, который дал о себе знать впервые в XIX веке, вначале во Франции, а позднее и в других странах европейской культуры. Становление этой концепции обычно датируют первой половиной XX века. Ее первопроходцами считаются француз Адольф Ландри [Landry 1909; 1933; 1934] и американец Уоррен Томпсон [Thompson 1929], а формулирование ее в окончательной форме связывают с именем Фрэнка Ноутстайна и его коллег, работавших в Принстоне в 1940-е - 1950-е годы. Дж. Колдуэлл полагал, что «современная теория демографического перехода появилась почти в зрелой форме в статье Ноутстайна в 1945 г.» [Caldwell 1976: 323]. Мне же кажется, что основные идеи концепции демографического перехода были сформулированы Спенсером за сто лет до Ноутстайна и, что особенно важно, на более высоком уровне обобщения.

Согласно представлениям принстонских демографов, как они были сформулированы Ф. Ноутстайном в 1945 г., «процесс модернизации в Европе и в заморской Европе привел к росту уровня жизни, новому контролю над болезнями и снижению смертности» в то время как рождаемость оставалась высокой, что и обусловило быстрый рост населения [Notestein 1945: 40-41]. Впоследствии этот рост распространился на весь мир, но он должен прекратиться, потому что «контроль смертности без контроля рождаемости невозможен», «рождаемость должна упасть достаточно, чтобы положить конец эпохе роста» [Там же: 57].

Тогда же термин «демографический переход» впервые появился в названии статьи, автор которой К. Дэвис развивал те же идеи, что и Ноутстайн [Davis 1945]. Промышленная революция и сопряженные с ней перемены обусловили быстрое снижение смертности, за которым последовало снижение рождаемости, а в конечном счете, - установление «нового демографического баланса». Но так как снижение рождаемости отставало от снижения смертности, то между ними возник разрыв, приведший к огромному росту европейского населения. Этот этап оказался временным, снижение рождаемости «догоняет», а иногда и «перегоняет» снижение смертности, вследствие чего численность населения в странах Западной Европы снова становится стабильной или даже убывающей. Но так как снижение смертности распространилось теперь на страны неевропейской культуры, то туда переместился и демографический взрыв, обусловленный лагом между снижением смертности и рождаемости. Впрочем, и здесь этот лаг - временное явление, и «вполне вероятно, что в следующем столетии будет достигнут пик роста населения всего мира, а новый демографический баланс распространится повсеместно» [Там же: 11]. 
Bce эти идеи, порожденные осмыслением европейской и глобальной демографической ситуации середины - второй половины XX века, казались очень новыми, но вот что писал почти за сто лет до этого в середине XIX века, когда этой ситуации не существовало и не было даже самого слова «демография», Герберт Спенсер.

«Пока рождаемость вида ${ }^{1}$ более чем достаточна, чтобы сбалансировать его сокращение в результате смертности, население будет продолжать увеличиваться... Изменения не могут прекратиться до тех пор, пока темпы размножения не будут равны темпам вымирания; иными словами, они никогда не прекратятся, пока каждая пара в среднем не будет доводить до зрелости только двоих детей» [Spencer 1852: 500] (в более поздней формулировке: до тех пор, пока в среднем каждая пара не будет иметь столько детей, сколько необходимо для создания следующего поколения родителей, равного по численности предыдущему поколению [Spencer 1891b: 504]; в самой же последней формулировке речь идет о том, что «человек, приближаясь к равновесию между его природою и постоянно изменяющимися условиями его неорганической среды, а также к равновесию между его природою и требованиями социального быта, в то же время приближается к такому низшему пределу плодовитости, при котором равновесие населения поддерживалось бы нарождением лишь того количества детей, которое уносится смертью в старости» [Спенсер 1899: 311; Spencer 1910: 538].

По-видимому, из этого следует, что «каждая пара будет редко производить на свет более двух потомков (курсив наш. - А.В.), так как при резко возросшей способности сохранять жизнь, что предполагают [наши] гипотезы, уровень младенческой и юношеской смертности должен стать очень низким» [Spenser 1852: 501].

Этот вывод 1852 г. также был несколько переформулирован впоследствии. «Хотя количество преждевременных смертей в потомстве может, наконец, сильно уменьшиться, однако оно никогда не понизится до того, чтобы среднее количество потомков каждой пары могло спуститься до двух. Возможно, что пределом будет некоторое число между двумя и тремя, - число, которое, впрочем, вероятно, не будет совершенно постоянным, а будет то несколько увеличиваться, то несколько уменьшаться, согласно с тем, как изменения в физических и социальных условиях будут увеличивать или уменьшать стоимость самосохранения» [Спенсер 1899: 309; Spencer 1910: 535].

Как видим, оценка Спенсером уровня, до которого может опуститься рождаемость, несколько изменилась (хотя и не принципиально), но общая идея неизбежности перехода от равновесия высокой смертности и высокой рождаемости к равновесию низкой смертности и низкой рождаемости, т. е. того, что и понимается сейчас под «демографическим переходом», выражена предельно ясно.

\footnotetext{
${ }^{1}$ Спенсер пользовался словом race, которое можно перевести как вид, но, конечно, не в том смысле, в котором его употреблял Дарвин, использовавший слово species (статья Спенсера, о которой идет речь, была написана до появления знаменитой книги Дарвина о происхождении видов). Все же оба эти слова в английском языке в той или иной степени синонимичны, и я использую в русском переводе не слово раса, как это делали дореволюционные переводчики Спенсера, а слово вид, но его, конечно, надо понимать не в буквальном дарвиновском смысле.
} 
Этот переход включает в себя самые разные стороны перемен в демографическом бытии, как правило, очень важные. Но все же сердцевину переживаемых всеми обществами демографических перемен составляет переход к низкой рождаемости, именно он дает основания говорить о смене «стратегии размножения» вида Homo sapiens [Вишневский 2014; Vishnevsky 2014]. Он в свою очередь порождает два фундаментальных и взаимосвязанных вопроса. Один из них - вопрос о причинах снижения рождаемости, второй - о пределах, до которых может идти такое снижение.

Спенсер, как и современная демографическая теория, дает свой ответ на оба вопроса. В этой статье нас интересует в первую очередь первый из них, объяснение Спенсером причин предсказанного им снижения рождаемости. Его объяснение, как мне кажется, не утратило своего значения и может вполне успешно конкурировать с большинством сегодняшних объяснений снижения рождаемости в ходе демографической революции (демографического перехода).

Второй вопрос не менее важен, но он заслуживает отдельного рассмотрения.

\section{ПРИЧИНА СНИЖЕНИЯ РОЖДАЕМОСТИ У СПЕНСЕРА}

Как справедливо заметил Д. ван де Каа, утверждение, что современные демографические переходы (он говорит о двух переходах - «первом» и «втором») следует рассматривать как результат социальных изменений - это трюизм. Очевидно, что в их основе «не может быть ничего, кроме изменений в структуре, культуре и технологии обществ. Но что именно привело к демографическим изменениям? Каковы были решающие факторы?» [van de Каa 2010].

Ван де Каа попытался каталогизировать имеющиеся ответы на эти вопросы и пришел к выводу, что имеется огромное количество «закрепившихся нарративов», объясняющих переход с разных позиций, указывающих на разные «факторы» и «детерминанты» снижения рождаемости, не противоречащих действительности, но не складывающихся в общее объяснение. В этой связи он вспоминает знаменитый фильм Акиро Куросавы «Расёмон», в котором разные люди излагают разные версии одного и того же наблюдавшегося ими события.

Более общие нарративы распадаются на субнарративы, так что «поиск детерминант прокреативного поведения и его изменений в течение последнего полувека лучше всего интерпретировать как разработку ряда субнарративов с разных дисциплинарных точек зрения и направлений» [van de Каa 1996: 389]. Ван де Каа не отрицает полезности большого числа суб-нарративов для понимания конкретных особенностей места и времени, но полагает, что оно едва ли полезно, когда речь идет о «поисках «истинных» или «фундаментальных» движущих сил, лежащих в основе перехода» [Там же: 389].

Множество нарративов имеет иерархическую структуру, и существует связь между их местом в иерархии и степенью содержащегося в них обобщения: чем выше это место, тем выше и потенциал обобщения. На противоположных полюсах лежат «очень общее объяснение уровней и изменений рождаемости с точки зрения технологии/биологии, 
структуры и культуры и очень конкретное объяснение частного случая в небольшой местности, где вполне могут преобладать эффекты, обусловленные предшествующей историей и институциональными изменениями» [Там же: 429].

Если говорить о самых высоких уровнях обобщения, претендующего на большую или меньшую универсальность объяснения перехода к низкой рождаемости, то современные демографы-теоретики, по большей части, связывают этот переход с универсальными процессами «модернизации» или «вестернизации», с промышленной революцией, индустриализацией, урбанизацией, ростом уровня образования, в том числе женского, распространением наемного труда, «постматериалистических ценностей», ростом гендерного равенства и др.

Наблюдаемые факты повсеместно подтверждают наличие таких связей, что, как полагают исследователи, и убеждает в детерминированности снижения рождаемости всеми указанными социальными и экономическими процессами. Но как мог прийти к выводу о том, что «каждая пара будет редко производить на свет более двух потомков», Спенсер, писавший об этом тогда, когда перечисленные только что перемены, да и то не все, едва начинались?

Ответ заключается в том, что уровень обобщения «нарратива» Спенсера был самым высоким из всех возможных и полученный им вывод не нуждался ни в каких субнарративах.

Статья Спенсера «Теория народонаселения, основанная на общем законе плодовитости животных» [Spencer 1852], в которой сформулирован этот вывод, уже своим названием указывает на то, что он опирается не столько на опыт человеческого общества, сколько на опыт природы. Статья опубликована за семь лет до появления «Происхождения видов» Дарвина, но в ней достаточно ясно выражена идея об эволюции форм жизни от простейших до человека, и соответственно, об эволюции двух неразделимых основополагающих свойств любой из этих форм - размножения вида и развития индивида. Эти свойства всегда находятся в обратной зависимости. «Когда из-за низкого уровня организации способность противостоять внешним опасностям мала, нужна большая плодовитость, чтобы компенсировать последующую смертность; в противном случае вид должен исчезнуть. Когда, наоборот, высокая развитость (high endowments) дает большую способность к самосохранению, необходима соответствующая этому низкая плодовитость» [Там же: 476].

В этой системе координат Спенсер рассматривает процессы размножения не только в природе, но и в обществе. Основная идея заключается в том, что у простейших организмов процессы жизнедеятельности и размножения не дифференцированы, размножение есть цель жизнедеятельности, достижением которой она и заканчивается. По мере же усложнения форм жизни размножение выделяется в отдельную функцию и занимает все меньшее место в жизнедеятельности, высвобождая пространство для развития других специализированных функций, а значит, и для совершенствования индивидуальных организмов. В терминах Спенсера это «антагонизм размножения и индивидуализации». 
Отталкиваясь от этих соображений, Спенсер и пришел к глубоким обобщениям, касавшимся соотношения и развития всего живого, и сформулировал свой «аксиоматический» закон сохранения видов. «Пока какой-либо вид продолжает существовать, силы разрушающие и сохраняющие его силы должны постоянно стремиться к равновесию. Если разрушительные силы уменьшаются, вид должен постепенно становиться все более многочисленным до тех пор, пока, вследствие недостатка пищи или увеличения числа врагов, разрушительные силы снова не уравновесятся с сохраняющими. Если, наоборот, разрушительные силы возрастают, вид должен уменьшаться, пока благодаря пище, становящейся относительно более обильной, или сокращению числа врагов, умирающих от голода, разрушительные силы опускаются до уровня сохраняющих сил. Если разрушающие силы будут иметь такую силу, что ответ на них не может быть найден (например, значительные изменения климата), вид вымирает и исчезает. Таков, следовательно, обязательный закон сохранения вида; когда виды перестают ему соответствовать, они исчезают» [Там же: 476].

Хотя социальная жизнь у Спенсера не тождественна биологической, на нее также распространяются общие «законы организации». К ним относится и «закон сохранения вида», говорящий об обратной зависимости способности сохранять жизнь и способности к размножению. Этот закон, согласно Спенсеру, справедлив и для человека.

Логика его рассуждений, на первый взгляд, напоминает логику Мальтуса, но, на самом деле, она сильно от нее отличается. Отличие заключено уже в исходном пункте. Мальтус исходил из того, что смертность на протяжении всего времени существования человека не менялась. «В течение всего периода, относительно которого мы имеем достоверные исторические свидетельства, не произошло никакого увеличения в естественной продолжительности человеческой жизни $<\ldots>$ В пользу предположения об увеличении продолжительности человеческой жизни мы не находим ни одного постоянного, достоверного признака с момента сотворения человека до настоящего времени» [Мальтус 1993: 25-26; Malthus 1998: III.1.14, III.1.18]. Это придает закону народонаселения Мальтуса внеисторический характер. Население всегда растет быстрее средств к существованию, что, собственно, и делает неизбежной высокую смертность. Его призывы к снижению рождаемости не привязаны к каким-либо историческим переменам, это универсальный рецепт на все времена.

У Спенсера все не так или, во всяком случае, не совсем так. Закон сохранения вида - исторический закон в том смысле, что, хотя он действует на всех этапах эволюции жизни на Земле, противоречие между размножением вида и развитием индивида на каждом новом этапе эволюции разрешается все более эффективным способом (т.е. все больше в пользу развития индивида). Этот прогресс обеспечивается на организменном уровне, средняя плодовитость организмов того или иного вида - биологическая константа. С точки зрения Спенсера, человек стоит в том же ряду, что и любой биологический вид. Но соотношение между способностью человека к размножению и его способностью сохранять жизнь, утверждает он, на протяжении истории не остается постоянным. «В целом цивилизация увеличивает способность людей сохранять жизнь» [Spencer 1852: 496], а «более высокая способность сохранять жизнь в этом случае, как и во всех других, неизбежно влечет за 
собой уменьшение способности к размножению» [Там же: 497], в конечном счете снижение рождаемости.

Снижение рождаемости, в рамках представлений Спенсера, обусловлено стремлением системы к равновесию - разрушающие и сохраняющие вид силы «должны постоянно стремиться к равновесию», это входит в понимание Спенсером «закона сохранения вида» [Там же: 475]. А антагонизм размножения и индивидуализации не только полностью соответствует этому априорному закону, справедливому для всех «от монады до человека», но, постоянно эволюционируя и принимая новые формы, в конечном счете «обеспечивает окончательное достижение высшей формы этого сохранения - формы, при которой количество жизни (amount of life) будет максимально возможным, а число рождений и смертей - наименее возможным» [Там же].

Важно то, что Спенсеру для объяснения снижения рождаемости не нужны никакие «нарративы», никакое обращение к конкретным детерминантам или факторам этого снижения. Оно есть проявление априорного «закона сохранения вида», изначально предполагающего равновесие «разрушающих» и «сохраняющих» сил, действию которых подвергается любой вид живых существ. Этот закон Спенсер вывел, обобщая известные ему факты об эволюции жизни на Земле, и если согласиться с этим обобщением, то не может возникнуть вопрос, почему жизнь устроена именно так, подобно тому, как не может возникнуть вопрос, почему дважды два всегда четыре. Существование этого объективного закона и служит единственной причиной снижения рождаемости.

\section{МЕХАНИЗМ СНИЖЕНИЯ РОЖДАЕМОСТИ ПО СПЕНСЕРУ}

Если что и нуждается в объяснении, то это не причины снижения рождаемости, а ее механизм. Не почему, а как происходит снижение рождаемости, когда этого требует поддержание необходимого равновесия, - вот вопрос, на который тоже пытается ответить Спенсер. Что происходит со способностью человека к размножению, когда возрастает его способность сохранять жизнь?

Цепочка зависимостей, которую прослеживает Спенсер, такова. Снижение смертности делает прежнюю рождаемость избыточной, а «избыток рождаемости влечет за собой постоянное давление населения на средства к существованию» [Там же: 498]. Растущее давление избыточного населения создает стимулы для развития производства, образования, науки, порождает «непрекращающийся спрос на умение, ум и самоконтроль» [Там же]. «Контраст между тихоокеанским островитянином, чьи потребности удовлетворяются природой, и англичанином, которому поколение за поколением приходилось развивать все возрастающие знания и навыки, чтобы обеспечить удовлетворения своих потребностей, сразу иллюстрирует необходимость и последствия такой дисциплины. И если это признается, то нельзя отрицать, что дальнейшее развитие такой дисциплины, возможно, в еще более интенсивной форме, должно привести к дальнейшему прогрессу в одном направлении - дальнейшему расширению нервных центров и дальнейшему снижению рождаемости» [Там же: 499]. «Расширение нервных центров» Спенсер понимает буквально, в физиологическом смысле, и даже приводит в 
доказательство своей мысли сравнение размеров мозга у представителей «более цивилизованных» и «менее цивилизованных» рас.

Все эти рассуждения Спенсера, по сути, служат продолжением его размышлений по поводу того, что «у всех видов позвоночных степень плодовитости меняется в обратном соотношении с развитием нервной системы» [Там же: 493], «способность сохранять индивидуальную жизнь во всех случаях измеряется развитием нервной системы» [Там же: 496], так что «если нервная система изменяется непосредственно как способность сохранять жизнь, она должна изменяться в обратном отношении к способности к размножению» [Там же].

Сегодня едва ли кто-нибудь думает, что ставшая массовой низкая рождаемость объясняется понизившейся физиологической плодовитостью людей, а ничего иного обращение к возможностям нервной системы человеческого организма объяснить не способно. Может быть, поэтому фигура Спенсера с этикеткой «представителя биологического подхода» задвинута на дальнюю полку музея истории демографической мысли.

Но если можно согласиться с тем, что объяснение Спенсером механизма снижения рождаемости не выдерживает критики и забыто не без основания ${ }^{2}$, то с его объяснением причин такого снижения дело обстоит иначе. Его отправлять в музей еще рано.

\section{«ЛИНИЯ СПЕНСЕРА» В СОВРЕМЕННОЙ ДЕМОГРАФИЧЕСКОЙ ТЕОРИИ}

Согласно Спенсеру, снижение рождаемости есть закономерный ответ на успехи в «сохранении жизни», т. е. в снижении смертности. Сейчас связь снижения рождаемости со снижением смертности представляется очевидной, но она была осознана не сразу, как и сам факт устойчивого снижения смертности - феномена, проявившегося лишь в XIX веке. Как утверждает Шенэ, на эту связь еще в середине XIX века обращал внимание изобретатель слова «демография» Ашиль Гийяр, так что уже тогда «идея механизма перехода существовала в зародыше» [Chesnais 1986: 7]. Любопытно, что Шенэ не упоминает Спенсера, у которого эта идея была выражена с очень большой определенностью. Но в целом представления о тенденциях рождаемости и смертности и их связи между собой долгое время были очень смутными.

Как писал, например, в конце XIX века тот же Нитти, «увеличение рождаемости в Германии с половины настоящего столетия, и в особенности в последние двадцать лет,

\footnotetext{
2 Впрочем, и здесь нужно сделать серьезные оговорки, в известном смысле реабилитирующие Спенсера. Хотя главным механизмом снижения рождаемости во всех развитых странах, несомненно, стал социально детерминированный “birth control”, исследователи отмечают и не зависящее от него существенное снижение физиологической плодовитости во всех странах, совершивших демографический переход. В частности, недавно группа исследователей из разных стран, выполнившая метаанализ нескольких тысяч англоязычных публикаций за 1981-2013 гг., пришла к выводу о систематическом снижении количества сперматозоидов в мужской сперме. Оно «значительно снизилось среди мужчин из Северной Америки, Европы и Австралии в течение 1973-2011 гг., причем снижение составило 50-60\% среди мужчин, отобранных независимо от рождаемости, без каких-либо признаков «выравнивания» в последние годы» [Levine et al. 2017: 654].
} 
приняло размеры настоящего перенаселения <..> Масса народонаселения непредусмотрительно и беспорядочно размножалась» [Нитти 1898: 70; Nitti 1894: 40-41]. Нитти ссылался при этом на немецких авторов. Между тем никакого роста рождаемости в Германии второй половины XIX века не было, напротив, рождаемость снижалась, но смертность снижалась еще быстрее, что и обусловило ускорение роста населения (рисунок 1). В начале XX века, когда демографические перемены осознавались лучше, «такой автор, как Вольф [Wolf 1912], анализируя возможные причины падения рождаемости в Германии, склонялся, прежде всего, к снижению смертности» [Chesnais 1986: 7].

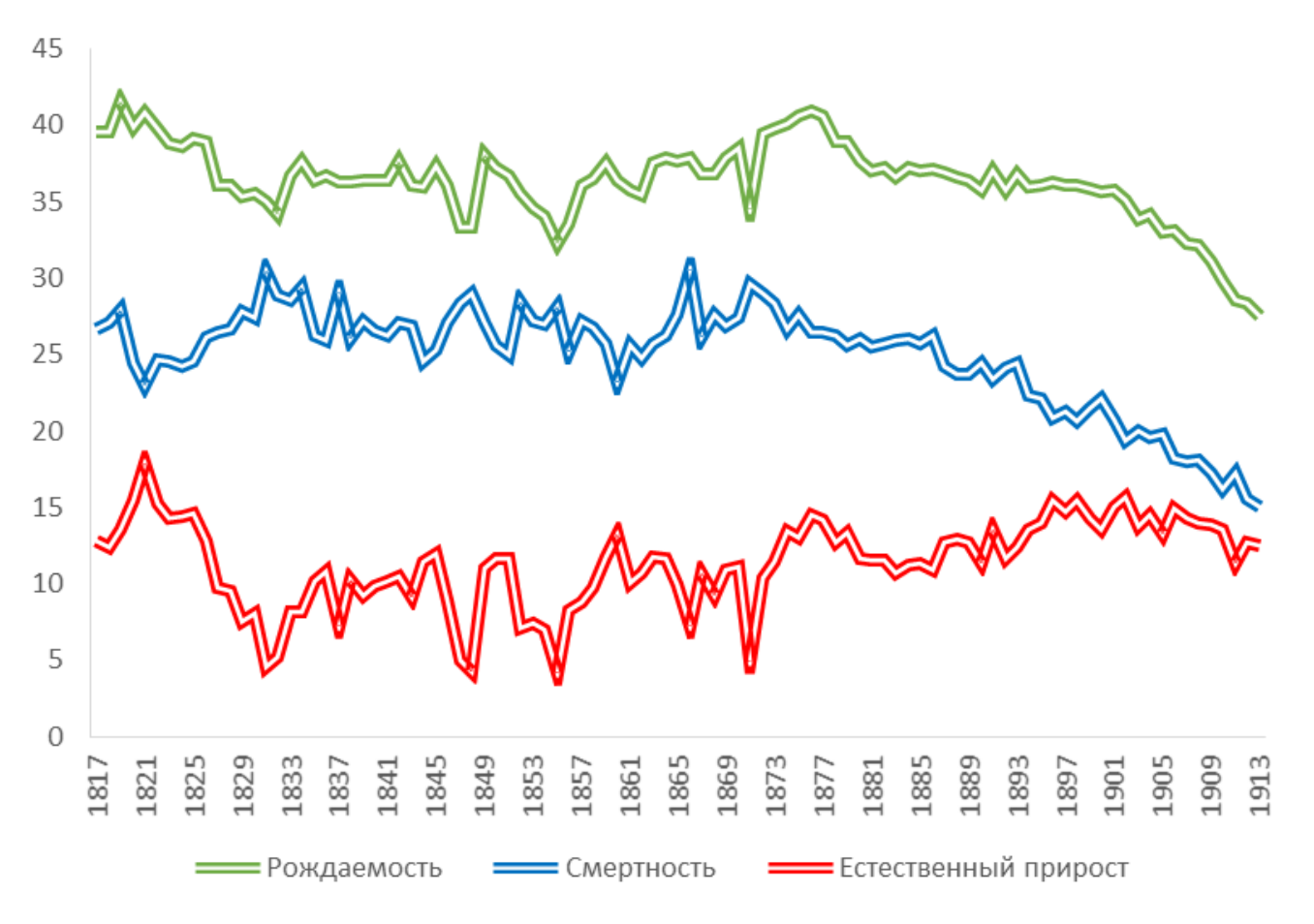

\section{Рисунок. Коэффициенты рождаемости, смертности и естественного прироста населения в Германии, 1817-1913 гг., \%о}

Источник: [Chesnais 1986: Annexes 2, 4].

К середине XX века обусловленность снижения рождаемости снижением смертности получила широкое признание. Переход от равновесия высокой смертности и высокой рождаемости к равновесию при низком уровне того и другого - главный постулат концепции демографической революции (демографического перехода), которая с этого времени заняла центральное место в теоретической демографии. Этот переход был осознан как важнейший элемент прогресса, потому что новый баланс между рождаемостью и смертностью, «баланс, менее расточительный, чем старый», привел к резкому повышению эффективности демографического, а потому и всего социального воспроизводства. «Новый тип демографического равновесия высвободил огромное количество энергии из вечной цепи воспроизводства, энергии, которая могла быть израсходована на решение других жизненных задач» и потому означал «поразительный выигрыш в эффективности человека» [Davis 1945: 1, 5]. Не знаю, был ли Кингсли Дэвис знаком с идеями Спенсера, но цитированные слова полностью соответствую представлениям последнего об историческом 
развитии антагонизма между размножением и индивидуализацией, равно как и об изменении их соотношения в пользу индивидуализации.

\section{ОТКЛОНЕНИЕ ОТ «ЛИНИИ СПЕНСЕРА» В СОВРЕМЕННОЙ ДЕМОГРАФИЧЕСКОЙ ТЕОРИИ}

Казалось бы, вопрос о снижении смертности как причине огромного снижения рождаемости - с традиционных 6-8, а то и большего числа рождений на одну женщину до нынешних 1-3 - абсолютно ясен.

Тем не менее со времен Ландри существует - и до сих пор гораздо более распространен - и другой подход, сторонники которого, не отрицая значения снижения смертности, все же считают его недостаточным для объяснения снижения рождаемости. «В прошлом ... рождения в семье могли быть многочисленными: умирало столько детей, что большие семьи встречались далеко не часто; сегодня при такой рождаемости большие семьи стали бы правилом. Но можно ли этим объяснить снижение рождаемости? Достаточно ли этого, чтобы утверждать, что неограниченное размножение порождало теперь не просто довольно небольшой риск больших семейных расходов, но вероятность столь большой нагрузки, чтобы это привело к ограничению воспроизводства? Представляется, что это не так» [Landry 1982: 37-38]. «Надо, следовательно, искать другое объяснение» [Там же: 39].

Нельзя сказать, что эта линия рассуждений Ландри выглядит убедительно обоснованной, но вот уже не одно поколение демографов следуют именно его логике, что само по себе кажется странным. Демографы прекрасно знают о снижении смертности как предпосылке снижения рождаемости, большинство из них разделяют представление о демографической революции как переходе от одного типа равновесия к другому, но при этом считают объективную необходимость нового демографического баланса недостаточным основанием для того, чтобы этот баланс утвердился во всех современных обществах. Следуя совету Ландри, они ищут «другое объяснение» падения рождаемости, его причины, не связанные непосредственно со снижением смертности. Как отмечает Д. Кирк, «хотя снижение смертности обычно упоминается как raison d'être снижения рождаемости, ему не часто отводят первостепенное место как причине снижения рождаемости» [Kirk 1996: 368]. Судя по всему, он считает такой подход оправданным, значительная часть его статьи посвящена именно обсуждению различных путей поиска причин (“search for causality”) снижения рождаемости.

Ван де Каа, признавая, что «снижение смертности играет центральную роль в объяснении первого демографического перехода», тут же отмечает, что оно «не является единственным причинным фактором снижения рождаемости. Как снижение смертности, так и снижение рождаемости, вероятно, будут реагировать на широкие изменения в обществе, такие как улучшение уровня жизни, усиление урбанизации, растущее достижительство и т. д.» [van de Kaa 2010].

В иерархической схеме объяснительных нарративов, предложенной ван де Каа, нарратив снижения смертности парадоксальным образом не только не занимает 
центрального места, но оказывается в числе многих нарративов самого низкого третьего уровня, тогда как на верхнем уровне находятся технологические, структурные и культурные детерминанты уровня рождаемости и его изменений, сопряженные с социальными изменениями, модернизацией или вестернизацией [van de Kaa 1996: 401].

Возможно, этот парадокс объясняется инерционностью научного мышления демографов, до сих пор не сумевших освободиться от идейного груза XVIII-XIX веков, когда вопросы о численности населения и еe росте обсуждались в основном в экономической литературе и виделись по большей части через призму экономических отношений и интересов. Весь XIX век прошел в спорах сторонников и противников Мальтуса, который велся в терминах соотношения числа людей и количества средств существования. Объяснить процессы, которые мы сегодня называем «демографическими», значило прежде всего связать их с какими-либо недемографическими, чаще всего экономическими, детерминантами.

Как полагает Ходжсон, к 1900 г. отношения между рождаемостью и социальноэкономическими факторами, в частности такими, как уровень благосостояния, социальный статус или проживание в городах, считались эмпирически установленными [Hodgson 1983: 5]. Эти отношения всегда понимались одинаково: таким факторам отводилась активная роль, прокреативное поведение людей рассматривалось как пассивный результат их воздействия, уровень рождаемости - как «зависимая переменная».

Последующие обобщения Ходжсон, как и многие другие, связывает с развитием теории демографического перехода, как она сложилась к середине XX века. Одно из главных ее утверждений заключалось в том, что по мере того, как аграрные сельские общества преобразуются в индустриальные и городские, они совершают переход от режима высоких к режиму низких показателей смертности и рождаемости. Само по себе это утверждение не вызывает возражений, но проясняет ли оно вопрос о детерминации изменений в рождаемости?

Влияние индустриализации, урбанизации, модернизации в широком смысле на смертность очевидно. «Весь процесс модернизации в Европе и заморской Европе привел к росту уровня жизни, новому контролю над болезнями и снижению смертности» [Notestein 1945: 40]. Рождаемость же, как отмечал Ноутстайн, оказалась «гораздо менее восприимчивой к процессам модернизации», но в конце концов и она стала снижаться, постепенно распространившись на всю Европу, Северную Америку, Австралию и Новую Зеландию. Важно понять, пишет он далее, причины тенденции, которая позволила населению этих регионов «поставить под контроль свою рождаемость с тем, чтобы привести ее уровень в соответствие с низким уровнем смертности, возможным в современных условиях» [Там же: 41].

Как мне представляется, в этом месте рассуждение Ноутстайна подошло к логической развилке, от которой можно было двигаться в разных направлениях. Он практически сказал, что модернизационные перемены, обусловив снижение смертности, привели к разбалансировке системы и потребовали снижения рождаемости для восстановления нарушенного баланса. На этом поиск причин этого снижения можно было бы остановить. 
Но вопреки собственной логике Ноутстайн стал выстраивать параллельный объяснительный ряд, пытаясь найти другие, не связанные со снижением смертности, социальные и экономические причины и факторы снижения рождаемости, подобные тем, которые легко было указать, когда надо было объяснить снижение смертности. Этот путь приводит его к утверждению, что рождаемость снижается «в ответ на резкие изменения в социально-экономической обстановке, которые коренным образом изменили мотивы и цели людей в отношении размера семьи» [Notestein 1945: 41].

С моей точки зрения, это утверждение вдвойне противоречиво.

Во-первых, двусмысленность содержится уже в самом словоупотреблении, в отождествлении рождаемости с размером семьи, здесь, по сути, происходит элементарная подмена понятий․․ Размер семьи, т. е. то, в отношении чего у людей действительно могут быть мотивы и цели, зависит не только от числа рожденных детей, но и от их выживания, т. е. от смертности; при снижении смертности рождаемость может снижаться, но не потому, что цели людей в отношении размера семьи изменяются, а как раз потому, что они остаются прежними.

Во-вторых же, из центрального тезиса теории демографического перехода о восстановлении баланса рождений и смертей на уровне общества следует, что новый баланс должен восстановиться и на уровне семьи, а значит, и цели людей в отношении размера семьи должны остаться прежним, и именно поэтому рождаемость должна снижаться. Любопытно, что это очень хорошо понимал Спенсер: «из того факта, что в целом цивилизация увеличивает способность сохранять жизнь, мы можем понять, что существует некое влияние, которое требует такого снижения [рождаемости]» [Spencer 1852: 496].

Ноутстайн, видимо, рассуждал иначе. Он конструирует свой «нарратив», пытаясь конкретизировать те социально-экономические изменения, которые, по его мнению, непосредственно побуждают людей рожать меньше детей. «Большинство из них сосредоточено вокруг растущего индивидуализма и повышающегося уровня массовых притязаний, которые развиваются в условиях городской жизни в промышленных центрах... Все эти перемены вели к тому, что многодетные семьи становились все более обременительным и дорогостоящим делом... для населения, все более освобождавшегося от старых табу и все чаще желающего решать свои проблемы, а не мириться с ними» [Notestein 1945: 42].

В этом рассуждении Ноутстайна, созвучном цитированным выше словам Ландри, нет упоминания о снижении смертности, и в этом смысле оно представляет собой шаг назад по сравнению с Ландри, у которого все же растущее бремя семейной нагрузки связывается с ростом числа выживающих детей. В рассуждении Ноутстайна эта связь отсутствует, как

\footnotetext{
3 Такое отождествление вообще характерно для англоязычной литературы, где выражение "family size" нередко употребляется как синоним числа рождений: "Family size (the mean number of children in the family) decreased by 61 percent from a high of 7.3 for women born in 1867-1870 to 2.8 for women born in 1951-1955" [Encyclopedia of Sociology 2018]. В русскоязычной литературе такая подмена понятий часто происходит при использовании термина «детность», который неявно отождествляется с рождаемостью, хотя на самом деле имеет другой смысл.
} 
будто такого факта не было вовсе, а все дело было только в изменении внешних по отношению к семье экономических и социальных обстоятельств. Как ни странно, именно эта позиция оказалась наиболее привлекательной для последующих поколений демографов-теоретиков.

Интересно проследить эволюцию взглядов одного из главных представителей Принстонской демографической школы Кингсли Дэвиса. Впервые он обратился к вопросу о снижении рождаемости в статье 1937 г., и тогда он объяснял его тем, что урбанизация, индустриализация и рост мобильности разрушают семейную организацию общества и подрывают роль семьи как главного института воспроизводства населения [Davis 1997]. О снижении смертности даже не упоминается, ясно, что тогда этот аргумент не попал в поле зрения автора статьи.

В статье 1945 г. акценты расставлены по-иному. С одной стороны, в ней содержатся аргументы, близкие к тем, которые сам Дэвис приводил в 1937 г., или к тем, какие мы находим у Ноутстайна («конкурентоспособное, индивидуалистическое, городское общество... сделало большие семьи помехой, а не благословением» [Davis 1945: 5]). С другой же стороны, в этой статье содержится указание на огромное снижение младенческой смертности, которое, способствуя увеличению количества больших семей, создало самостоятельные стимулы к сокращению числа рождений [Davis 1945: 5].

Впоследствии именно эта мысль получила развитие в статье Дэвиса о демографических изменениях и ответах на них в современной демографической истории [Davis 1963]. Эта статья - одна из самых важных публикаций во всей литературе о демографическом переходе. В ней, в частности, с большой определенностью высказана мысль о том, что «снижение смертности создавало затруднения для человека, увеличивая его семью» и сделало привычное поведение семей помехой в их стремлении воспользоваться возможностями, предоставляемыми развивающейся экономикой. Соответственно они начали менять свое репродуктивное поведение [Davis 1963: 352].

Мне кажется, что в этой статье Кингсли Дэвис выступает, скорее, как сторонник первого подхода к объяснению изменений в рождаемости, во всяком случае, приближается к признанию демографической логики ее снижения. К сожалению, в дальнейшем эта логика не получила у него развития. В конце жизни Дэвис вернулся к своим первоначальным взглядам о том, что современный индустриализм ослабляет семью, превращает ее в «социальный рудимент», неспособный обеспечить необходимый для воспроизводства населения уровень рождаемости после того, как в развитых странах этот уровень уравновесился с новым (низким) уровнем смертности [Davis 1986: 59-63], т. е. после завершения демографического перехода.

Недемографическая логика объяснения снижения рождаемости, да и вообще ее детерминации, возобладала не только во взглядах американских классиков теории демографического перехода. Она практически безраздельно господствует в работах большинства демографов, придерживающихся этой теории, не говоря уже о тех, кто с нею не согласен. Как отмечалось в обзоре теоретических представлений о низкой рождаемости, сложившихся к 1990 г., «все сходятся на том, что снижение рождаемости было в основном 
обусловлено промышленной революцией, как это описал Ноутстайн» [Caldwell, Schindlmayr 2006: 355].

Этой же логики придерживается и ван де Каа. «Переход от семейного производства к наемному оплачиваемому труду, который сопровождал индустриализацию и урбанизацию, снизил экономическую полезность детей. Они больше не могли служить в качестве дешевой рабочей силы для родительских фермы или бизнеса, но зато требовали инвестиций в образование и подготовку, чтобы дать им реальный шанс в жизни... Большое число детей может означать размывание семейного имущества, такого как земля, после смерти родителей, так что контроль над рождаемостью стал разумной стратегией. Секуляризация уменьшила влияние церкви и повысила готовность супружеских пар практиковать планирование семьи» [van de Каa 1987: 5].

Немало подобных рассуждений можно найти и в отечественной литературе, приведем один из недавних примеров. «В прошлых аграрных обществах семья была производственной ячейкой, отношения между членами семьи во многом определялись производственными факторами. Дети имели значение для родителей как работники, помощники в хозяйстве, его наследники, воины-защитники хозяйства. Большое число детей способствовало благосостоянию семьи (рода, племени), росту авторитета родителей в обществе... По мере развития индустриальной цивилизации все вышеназванные роли постепенно переходят от семьи к другим социальным институтам. Происходит поляризация семейных и внесемейных интересов и способов жизнеобеспечения... Дети постепенно теряют свою экономическую полезность и начинают удовлетворять в основном лишь эмоциональные потребности родителей, для чего в большинстве случаев, очевидно, достаточно именно 1-2 детей» [Антонов, Борисов 2011: 245-246].

Едва ли не самым удивительным во всех подобных рассуждениях кажется ставшая привычной односторонняя трактовка давно известной корреляции между падением рождаемости и развитием важнейших социальных институтов современного мира. Например, хорошо известна связь между уровнем рождаемости и ростом гендерного равенства в получении образования и профессиональной трудовой деятельности. Это растущее равенство неизменно трактуется как причина снижения рождаемости и никогда не рассматривается как его следствие. Между тем, если бы рождаемость не снижалась и женщина по-прежнему должна была бы проводить всю свою жизнь в состоянии беременности, вскармливания младенцев и ухода за ними, ни о каком гендерном равенстве не могло быть и речи. Оно стало возможно только тогда, когда резко повысилось выживание детей: исходная предпосылка заключалась в огромном снижении смертности.

То же следует сказать и в отношении многих других перемен, в которых часто видят причину снижения рождаемости, таких как изменение роли семьи и баланса семейных и несемейных интересов человека, семейных ролей и нравов, сексуальной морали и многое другое. Все это связано со снижением рождаемости, но не как причина, а как следствие. Снижение смертности сделало прежнюю высокую рождаемость ненужной, а это повлекло за собой цепочку перемен, буквально преобразивших индивидуальную и социальную жизнь людей. Все должно было измениться и действительно стало меняться. 
Если вывести за скобки снижение смертности, то все остальные экономические и социальные факторы, с которыми ассоциируется снижение рождаемости, - это не причины, а лишь части механизма этого снижения. Их действие приводит уровень рождаемости в соответствие с новым уровнем смертности и одновременно позволяет реализовать небывалый социальный выигрыш, который становится возможным на этом - финальном, с точки зрения Спенсера, - этапе развития «антагонизма размножения вида и развития индивида».

\section{МЕСТО СПЕНСЕРА В РОДОСЛОВНОЙ КОНЦЕПЦИИ ДЕМОГРАФИЧЕСКОГО ПЕРЕХОДА}

Хотя начало современного демографического перехода обычно датируется концом XVIII века, он набрал силу лишь позднее и был осознан только в первой половине XX века. Можно ли связывать демографические идеи Спенсера с этим переходом и вписывать их в родословную нынешних идей теоретической демографии?

Спенсер строил свои соображения, исходя из обобщений, относящихся ко всей истории жизни на Земле, и, казалось бы, на них никак не могли повлиять едва обозначившиеся процессы современной ему истории. Тем не менее круг его идей не был и не мог быть оторванным от общего движения европейской мысли его времени. А это было время, когда объективно переход уже шел и Европа начинала ощущать его демографические последствия, прежде ей неизвестные, население многих европейских стран росло необычно высокими темпами, и этот рост ускорялся.

Новая ситуация была осознана не сразу. Монтескье еще в середине XVIII века утверждал, что «население в большинстве европейских стран было многочисленнее, чем в настоящее время» [Монтескье 1955: 526; Montesquieu 1995: 284], в «Духе законов» есть глава, которая так и называется: «О том, как обезлюдел мир». Но постепенно центр тяжести смещается в сторону обсуждения вопросов, связанных не с возможностью обезлюдения мира, а напротив, с возможностью его перенаселения. Появляется идея «равновесия», и естественным образом возникает стремление понять природу регуляторов роста, способных или неспособных поддерживать такое равновесие.

Эволюцию взглядов на эти вопросы можно проиллюстрировать на примере трех эмблематических фигур истории демографической мысли: Зюсмильха, Мальтуса и Спенсера, каждый из которых отстоит от предшественника на расстояние примерно в полвека.

Зюсмильх: «Равновесие - это равновесие числа людей. Перенаселение привело бы ко всеобщей войне» [Süssmilch 1998: 43]. О подержании равновесия заботится Божественное Провидение. «Размножение это что-то меняющееся, так что Бог может очень легко его замедлить или ускорить в зависимости от состояния мира... Это простая вещь для Божественного Провидения. Для этого нужно только дать умереть несколько большему числу людей. И это можно сделать совершенно незаметно... Подобно тому как Бог может легко ускорить размножение, давая больше жизненной силы детям, чтобы они не умирали 
в таком количестве и так быстро, он может столь же легко замедлить его, позволяя умирать большему их числу» [Süssmilch 1998: 100].

Мальтус: Отвечая тем, кто «утверждает, что естественные препятствия к размножению населения совершенно достаточны для того, чтобы всегда сдерживать его в необходимых границах, а потому нет надобности в установлении еще иных препятствий», он замечает, что «в глазах рассудительного человека препятствие, находящееся в зависимости от благоразумия, не менее естественно, чем нищета или преждевременная смерть, которым мои противники, по-видимому, отдают предпочтение» [Мальтус 1993: 113-114; Malthus 1998, Appendix I, 1807: *6, *7]. Под «препятствиями, находящимися в зависимости от благоразумия» он понимает снижение рождаемости. «Если средства существования страны не допускают быстрого возрастания населения..., то неизбежно должно произойти одно из двух: или увеличение смертности от какой-либо иной причины, или уменьшение относительного числа рождений... Я ... выразил желание, чтобы произошло последнее» [Мальтус 1993: 113; Malthus 1998, Appendix I, 1807: *5-*6].

Спенсер: «Человек, приближаясь к равновесию между его природою и постоянно изменяющимися условиями его неорганической среды, а также к равновесию между его природою и требованиями социального быта, в то же время приближается к такому низшему пределу плодовитости, при котором равновесие населения поддерживалось бы нарождением лишь того количества детей, которое уносится смертью в старости» [Спенсер 1899: 311; Spencer 1910: 538]. «Избыток плодовитости, при посредстве постоянно производимых им изменений в окружающих человека условиях, сам есть причина дальнейшего развития человека; и ясно, что из этого вытекает то следствие, что производимое таким образом дальнейшее развитие человека само неизбежно ведет к уменьшению плодовитости» [Спенсер 1899: 305; Spencer 1910: 501].

У Зюсмильха о поддержании равновесия заботится Бог, Мальтус пытается возложить эту заботу на самих людей, Спенсер верит в регуляторные механизмы природы. Забегая несколько вперед, заметим, что современные демографы, мыслящие в категориях демографического перехода, часто полагают, что поддержание равновесия - сфера ответственности правительств, но к этому вопросу мы еще вернемся.

Есть одна очень важная, по крайней мере, с точки зрения демографа, черта, которая сближает Мальтуса и Спенсера и отдаляет их обоих от Зюсмильха. У Зюсмильха в качестве регулятора выступает смертность, а у Мальтуса и Спенсера - рождаемость.

Если мне будет позволено высказать мое мнение по поводу того, что составляет суть демографического перехода, - после того, как это пытались сделать столько светлых умов, - то я скажу, что эта суть заключается именно в смене регулятора. Роль регулятора демографической динамики перешла от смертности к рождаемости, и это - главное. Все остальное - лишь следствие этого уникального события, случившегося единственный раз не только в истории человеческого общества, но и во всей истории жизни на Земле.

Впервые о смене регулятора с необыкновенной силой сказал Мальтус - ведь он буквально требовал легитимизировать новый регулятор, - казалось бы, его и следует назвать отцом теории демографического перехода. Этому препятствует то, что как раз 
перехода Мальтус не видел. Его демографическая картина мира была статической: никакого увеличения продолжительности человеческой жизни с момента сотворения человека. Соответственно, вневременным был и его закон народонаселения.

Демографическая картина мира Спенсера - историческая, у человека «соотношение между его способностью к размножению и его способностью сохранять жизнь не остается постоянным», а «любое изменение соотношения, вероятно, будет связано со снижением рождаемости» [Spencer 1852: 496].

Указание Спенсера на «переходное состояние» оставляет место для толкований. Скорее всего, он просто имел в виду всю историю человечества, рассматривал рост «способности сохранять жизнь» как сопровождающий ее непрерывный процесс и так понимал «переходность», постепенно ведущую к конечному равновесию. Но и этом случае единственный шаг, который отделяет концептуальное видение Спенсером снижения рождаемости как адаптивной реакции на снижение смертности и вытекающее из этого нарушение равновесия от современных представлений о демографическом переходе, - это его локализация во времени.

Современная теория демографического перехода связывает снижение рождаемости с разного рода модернизационными процессами, среди которых ключевое место отводится индустриализации и урбанизации. Это автоматически маркирует момент начала перехода временем промышленной революции, иногда и политической революции во Франции и вписывает демографический переход в ряд фундаментальных перемен, характерных для начавшегося этими двумя революциями нового этапа истории, по крайней мере, европейской. Но во времена Спенсера эта временна́я граница, отметившая вступление в новый этап истории, еще не была осознана. Выражение «промышленная революция» изредка встречалось у разных авторов, но не вело ни к каким обобщениям. Такое обобщение можно впервые, пожалуй, встретить у Ф. Энгельса, но тогда оно не получило известности. Считается, что в широкий оборот много позднее его ввел А. Тойнби [Bezanson 1922].

Так что неудивительно, что шаг, который отделяет Спенсера от современных теоретиков демографического перехода, тоже был сделан позднее, если говорить о принстонских демографах, то через сто лет. Но если отвлечься от вопроса о временно́й локализации, то вся логическая схема перехода была очень четко прочерчена Спенсером.

В середине XIX века он уверенно предсказал не только рост, но и прекращение роста населения мира и создаваемого им демографического давления. «После того, как оно обусловит <...> заселение всего земного шара и утверждение во всех его обитаемых частях самого высокого состояния культуры, после того, как удовлетворение человеческих потребностей достигнет совершенства, после того, как способности людей получат полное развитие, необходимое для их деятельности, а их чувства придут в полное соответствие с требованиями социальной жизни - после того, как все это будет сделано, мы увидим, что давление населения, поскольку оно постепенно выполнит свою задачу, постепенно само подойдет к концу» [Spencer 1852: 500].

Именно сбывшиеся или сбывающиеся предсказания Спенсера о снижении рождаемости как способе восстановления нарушенного снижением смертности 
демографического баланса дают все основания считать его отцом концепции демографического перехода, возможно даже намного более проницательным, чем его общепризнанные более поздние теоретики, и в этом смысле до сих пор непревзойденным.

Его строго монистическое толкование снижения рождаемости очень последовательно. Развитие ведет к снижению смертности и появлению избыточной рождаемости, происходящие вследствие этого изменения приводят к ее снижению, а «единственный фактор, который должен был вызвать это изменение, - избыточность самой рождаемости» (курсив Спенсера) [Spencer 1852: 498], т. е. нарушение равновесия. Такое толкование не предполагает никакой другой каузальности.

Велико искушение сказать, что целые поколения исследователей трудились над своими «нарративами» зря, надо было просто почитать Спенсера. Конечно, это было бы большим упрощением. Но то, что это позволило бы сделать путь познания более коротким, несомненно.

Можно не знать ничего, кроме того, что сказал Спенсер, чтобы утверждать, что на первых порах реакция на снижение смертности всегда должна сильно зависеть от локальных особенностей и исторических различий. Ни одно общество не может пройти мимо открывающихся перед ним новых возможностей, однако скорость их осознания, последовательность использования, готовность к переменам, сила противодействия им и многие другие характеристики не могут не различаться. Поиски этих различий и отражаются в бесчисленных «нарративах», в меру полезных для понимания разного рода реальных ситуаций.

Но это отнюдь не поиски причин снижения рождаемости. То, о чем обычно говорят авторы «нарративов», - это НЕ ПРИЧИНЫ снижения рождаемости, а СЛЕДСТВИЯ появившейся возможности ее снижения. Это - способы реализации того небывалого выигрыша, который принесло снижение смертности, сделав возможным и необходимым ответное снижение рождаемости и, в конечном счете, переход к новой, намного более экономичной стратегии размножения вида Homo sapiens [Вишневский 2014; Vishnevsky 2014].

Логику всех «нарративов», структурированных ван де Каа, но понятную и независимо от его впечатляющей классификации, можно обобщить в одной фразе: цивилизация в ее современных формах и проявлениях сделала неизбежным снижение рождаемости. Логика же Спенсера противоположная: «избыток рождаемости сделал неизбежным процесс цивилизации» [Spencer 1852: 500]. Я думаю, что логика Спенсера более глубокая.

\section{НИЗКАЯ РОЖДАЕМОСТЬ И ПРОНАТАЛИСТСКАЯ ПОЛИТИКА}

«Демографическая революция» Ландри - это сигнал тревоги. «Человек все больше и больше ограничивает деторождение, приближая момент, когда человечество больше не будет воспроизводить себя полностью» [Ландри 2014; Landry 1933: 368]. «Встречается... эгоизм, который заставляет людей видеть в детях только дополнительные расходы и 
неудобства... И можно заметить, что такой эгоизм играет все большую и большую роль: мы видим, что среди линий поведения, которым могут следовать люди, все чаще выбираются те, что связаны с более последовательным ограничением рождаемости» [Ландри 2014; Landry 1933: 367]. Ландри постоянно подчеркивает опасность рассогласования демографических интересов индивида и общества и подводит к мысли о необходимости специальных мер, направленных на устранение этого рассогласования.

Эта позиция кажется очень убедительной и имеет огромное число последователей. Когда-то Франция была единственной страной, в которой задумывались о проведении правительством пронаталистской политики, сейчас трудно найти страну с низкой рождаемостью, которая не пыталась бы проводить такую политику. Тем не менее, как известно, рождаемость во всех этих странах остается ниже уровня замещения поколений, и единственное, что могут сказать инициаторы проведения такой политики, это то, что если бы политики не было, то рождаемость упала бы еще больше, - утверждение, которое невозможно проверить.

Казалось бы, Спенсер никак не мог предвидеть нынешнего всеобщего увлечения пронаталистской политикой. Однако, предсказывая снижение рождаемости в результате взаимодействия противоположно направленных сил, как он их понимал, он замечает: «Нужно только, чтобы вышеупомянутые действия и противодействия не встречали себе каких-либо искусственных препятствий. Я обращаю особое внимание на эту ограничивающую оговорку и специально на ней настаиваю; ибо подобные действия и противодействия, как до настоящего времени, так и теперь, встречают вмешательство со стороны правительства, а при наличии такого вмешательства в будущем они могут замедлить, если не совсем остановить дальнейшую эволюцию, которая в противном случае осуществилась бы сама» [Спенсер 1899: 307; Spencer 1910: 532].

Это - не случайное замечание, а отражение общих взглядов Спенсера на общество как на саморегулирующийся организм. Общество имеет множество потребностей, и его успешное функционирование предполагает определенную последовательность удовлетворения этих потребностей: более важные должны удовлетворяться раньше, чем менее важные. Всегда, стало быть, существует проблема выбора приоритетов.

Развивая логику Ландри, А. Сови, считавший себя его учеником и последователем, утверждал, что этот выбор нельзя доверять «рядовым» людям, их «познания в области сложного процесса воспроизводства населения слишком поверхностны для того, чтобы стремление выполнить свой моральный долг могло обеспечить демографическое равновесие» [Сови 1977: 226; Sauvy 1966: 164-165]. «Если провиденциальное равновесие с течением времени может приобрести некоторую устойчивость, то это произойдет лишь в результате того, что люди, чье назначение состоит в том, чтобы служить орудиями достижения этого равновесия, останутся верными своей миссии» [Сови 1977: 227; Sauvy 1966: 166].

Точка зрения Спенсера противоположная. В вопросе выбора приоритетов «суждению правительства нельзя вполне доверять», «это задача, которая не по силам ни одному правительству». «Обществу должна быть предоставлена свобода почувствовать, в чем оно более всего нуждается. Способ решения должен быть экспериментальный, а не 
теоретический». Поиски гражданами путей «устранения первоначально наибольшей несообразности» могут затрудняться привычками и предрассудками людей, но такие поиски «все-таки гораздо более надежны, чем суждения законодателей» [Спенсер 1999: т. 3: 1166-1167; Spencer 1910: 532].

\section{ЗАКЛЮЧЕНИЕ}

Цель этой статьи - проанализировать вклад Герберта Спенсера в демографическую теорию, прежде всего, в теоретическое осмысление феномена низкой рождаемости. Наша задача заключалась не просто в том, чтобы заполнить пробел в общепринятых представлениях об истории демографической мысли. Нам представляется более важным привлечь аргументацию Спенсера к современным дебатам о настоящем и будущем низкой рождаемости, исходя из предпосылки, что его аргументация не только не стала историческим раритетом, но и сегодня во многом опережает время.

Спенсер рассматривал человеческое общество как единый организм, и это часто дает основания упрекать его в подмене социальных объяснений биологическими. В некоторых случаях, как например, в случае объяснения снижения плодовитости человека развитием нервных центров, эти упреки справедливы. Но такие случаи - скорее исключение, чем правило. Вообще же Спенсер не отождествлял социальный организм с биологическим, не отрицал различия между ними, а лишь исходил из того, что это различие «не влечет за собою различия со стороны законов организации, которые одинаковы для обоих случаев; ибо необходимое условие каждой организации, а именно - возможность для всех частей организма влиять друг на друга - существует и в обществе, хотя оно и выполняется здесь не прямым, а косвенным путем» [Спенсер 1994: § 223; Spencer 1898: 462]. В этом рассуждении Спенсер предстает как один из ярких предшественников системного подхода, получившего развитие уже в XX веке.

Этот подход и до сих пор практически не нашел себе места в демографической теории. Но именно он, пусть и в ранних его формах, позволил Спенсеру подняться до очень высокого уровня обобщения и предсказать переход от равновесия высокой смертности и высокой рождаемости к демографическому равновесию при низком уровне того и другого. «Детерминанты» и «факторы», анализируя которые пытаются объяснить причины этого перехода современные демографы-теоретики, во времена Спенсера лишь едва обозначились на исторической сцене, многие из них еще не проявили себя, не были осознаны. Но они и не нужны были Спенсеру. Он понял главную, точнее сказать, единственную, причину снижения рождаемости - ее избыточность вследствие снижения смертности, которое он рассматривает как плод цивилизации, т. е. как социальный процесс.

Историки демографической мысли ведут родословную концепции демографического перехода от Адольфа Ландри и Уоррена Томпсона, иногда указывают на их предшественников, например, на Арсена Дюмона с его идеей «социальной капиллярности». Но если говорить о понимании подлинных причин снижения рождаемости как неотъемлемой части этого перехода, то решающее слово сказал именно Спенсер, и ничего нового к нему никогда не было добавлено. 
Другое дело, что это слово не было расслышано демографами. Идеи Спенсера не присутствуют в их работах, посвященных демографическому переходу. Об этом можно только пожалеть. Единственным утешением может служить лишь то, что демографы не одиноки в своем невежестве.

Спенсера хоронили не раз. Как писал в 30-е годы минувшего века Крейн Бринтон, «нам сейчас трудно понять, насколько большой интерес вызывали идеи Спенсера в его время... Он был личным наперсником странного и непонятного бога, которого он назвал эволюцией. Его бог предал его. Мы пошли дальше Спенсера» [Brinton 1933: 226-227]. Парсонс, цитируя Бринтона, в общем соглашается с ним, хотя и с оговоркой: «Конечно, нельзя утверждать, что все его мысли ныне несостоятельны, но мертва его социальная теория как целостная структура» [Парсонс 2002: 43; Parsons 1949: 3]. Однако действительно ли она мертва и так ли независимы системные взгляды на общество самого Парсонса от «организмических» взглядов Спенсера? Случайно ли автор предисловия к посмертному переизданию книги Парсонса «Социальная система» счел нужным подчеркнуть, что «в социальной теории, в использовании аналогий и метафор из биологических наук заключалась общая стратегия развития теоретических подходов к социальным системам», характерная, в частности, для эволюционной социологии Спенсера, а взгляды Парсонса на системные качества социальных отношений формировались под влиянием идей биологов Клода Бернара и Уолтера Кэннона [Turner 1991: x vii]? Важно не то, пошли ли исследователи $\mathrm{XX}$ в. дальше своих предшественников, живших на сто лет раньше, - иначе и быть не могло, - а то, шли ли они в том же направлении.

Как полагает Джонатан Тэрнер (не смешивать с цитированным выше Брайаном Тэрнером), методологические принципы Спенсера «использовались десятилетиями в самых разных эмпирических контекстах гораздо чаще, чем принципы, разработанные Марксом, Вебером и Дюркгеймом. Иногда такое использование признавалось, но чаще оставалось неизвестным, в результате чего многие идеи Спенсера были переоткрыты... Если бы социологи - теоретики и исследователи - начали XX век, имели в руках модели и принципы Спенсера, вполне вероятно, что социология была бы более зрелой наукой» [Turner 1981: 95].

К демографии это относится в еще большей степени.

\section{ЛИТЕРАТУРА}

Антонов А.И., Борисов В.А. (2011). Лекиии по демографии. Учебник для вузов. М.: Академический проект; Альма Матер. 584 стр.

Вишневский А. (2014). Демографическая революция меняет репродуктивную стратегию вида Ното sapiens. Демографическое обозрение, 1(1), 6-33. https://doi.org/10.17323/demreview.v1i1.1825

Ландри А. 2014 (1933). Демографическая революция. Демоскоn Weekly, 611-612. http://www.demoscope.ru/weekly/2014/0611/nauka02.php

Мальтус Т.P. (1993). Onыm о законе народонаселения. Антология экономической классики в двух томах. Т.2. М.: Эконов: 5-134.

Монтескье Ш. (1955). О духе законов. Избранные произведения. М.: Госполитиздат, 159733. 
Нитти Ф.С. (1898). Народонаселение и общественный строй. СПб. 342 с.

Парсонс Т. (2002). О структуре социального действия. М.: Академический Проект. 880 с.

Сови А. (1977). Общая теория населения. T.2. Жизнь населений. М.: Прогресс. 519 с.

Спенсер Г. (1899). Основания биологии. Т.2. Киев-СПб-Харьков: Южно-русское книгоиздательство Ф.А. Иогансона. 380 с.

Спенсер Г. (1994). Основания социологии. Что такое общество? В.И. Добреньков, Л.П. Беленкова (Ред.), Тексты по истории социологии ХІХ-ХХ вв. Хрестоматия. М.: Наука.

Спенсер Г. (1999). Опыты научные, политические и философские. В трех томах. Современный литератор. 1408 с.

Bezanson A. (1922). The early use of the term Industrial Revolution. The Quarterly Journal of Economics, 36 (2), 343-349.

Brinton C. (1933). English Political Thought in the Nineteenth Century. Ernest Benn Limited. London.

Chesnais J.-C. (1986). La transition démographique. Etapes, formes, implications économiques. Etude de séries temporelles (1720-1984) relatives à 67 pays. INED. Travaux et documents. Cahier no 113. PUF. 580 p.

Caldwell J., Schindlmayr T. (2006). Explanations of the fertility crisis in modern societies: A search for commonalities. In Caldwell J. Demographic Transition Theory (pp. 349-386). Springer.

Caldwell J.C. (1976). Toward a restatement of demographic transition theory. Population and Development Review, 2 (3-4), 321-366.

Davis K. (1945). The World demographic transition. The Annals of the American Academy of Political and Social science. Vol. 237. World Population in Transition, 1-11.

Davis K. (1963). The theory of change and response in modern demographic history. Population Index, 29 (4), 345-366.

Davis K. (1986). Low fertility in evolutionary perspective. Population and Development Review, Vol. 12, Supplement: Below-replacement fertility in industrial societies: Causes, consequences, policies, 48-65.

Davis K. (1997). Reproductive institutions and the pressure for population. Population and Development Review, 23(3), 611-624.

Encyclopedia of Sociology (2018). Family Size. Encyclopedia.com. 19 Aug. http://www.encyclopedia.com.

Hodgson D. (1983). Demography as social science and policy science. Population and Development Review, 9 (1), 1-34.

Kirk D. (1996). Demographic transition theory. Population Studies, 50(3), 361-387.

Landry A. (1909). Les trois théories principales de la population. Scientia.

Landry A. (1933). La révolution démographique. Economic Essays in Honour of Gustav Cassel. October 1933. Frank Cass and Company Limited 1967, 357-368. English translation (1987): Adolphe Landry on the Demographic Revolution: Population and Development Review, 13(4), 731-740.

Landry A. (1934). La révolution démographique. Paris, Recueil Sirey. 
Landry A. (1982). La révolution démographique. Études et essais sur les problèmes de la population. Paris: INED. 227 p.

Levine H. et al. (2017). Temporal trends in sperm count: a systematic review and metaregression analysis. Human Reproduction Update, 23(6), 646-659.

Malthus T.R. (1998). An Essay on the Principle of Population. [London 1798]. Electronic Scholarly Publishing Project. URL:

http://www.esp.org/books/malthus/population/malthus.pdf

Montesquieu Ch. (1995). De l'esprit des lois. Paris, Gallimard.

Nitti F. (1894). Population and the Social system. London: Sansonnenschein \& Co.

Notestein F.W. (1945). Population - the long view. In T. Schultz (Ed.), Food for the World (pp. 37-57). Chicago: University of Chicago Press.

Parsons T. (1949). The Structure of Social Action. A Study of Social Theory with Special Reference to a Group of Recent European Writers. The Free Press. Glencoe, Illinois. 817 p.

Spencer H. (1891a). The nebular hypothesis. Essays: scientific, political, \& speculative. Vol. 1. URL: http://www.gutenberg.org/files/29869/29869-h/29869-h.htm

Spencer H. (1891b). The Principles of Biology. Vol. 2. New York: D. Appleton and Company.

Spencer H. (1898). The Principles of Sociology. Vol. 1 New York: D. Appleton and Company.

Spencer H. (1910). The Principles of Biology. Revised and enlarged edition. New York: D. Appleton.

Süssmilch J.P. (1998). L'Ordre divine. Paris, INED.

Turner B.S. (1991). Preface to the new edition. In Parsons T. (Ed.), The Social System. Routledge.

Turner J.H. (1981). The forgotten theoretical giant: Herbert Spencer's models and principles. Revue européenne des sciences sociales, 19(59): 79-98.

van de Kaa D. J. (1987). Europe's Second Demographic Transition. Population Bulletin. 42(1), 57.

van de Kaa D. J. (1996). Anchored narratives: The story and findings of half a century of research into the determinants of fertility. Population Studies, 50 (3), 389-432.

van de Kaa D. J. (2010). Demographic transitions. In By Zeng Yi (Ed.), Encyclopedia of Life Support Systems (EOLSS). Demography, Vol. 1 (pp. 65-103). Oxford, UK: EOLSS Publishers.

Vilquin É. (2006). Histoire de la pensée démographique jusqu'en 1940. Démographie. Analyse et synthèse. Sous la direction de G. Caselli, J. Vallin et G. Wunsch. Vol. 7, Chapitre 97, 11-54. Paris, INED.

Vishnevsky A. (2014). The demographic revolution is changing the reproductive strategy of Homo sapiens. Demographic Review, English selection: 3-24. URL: https://demreview.hse.ru/article/view/3155/2739

Wolf J. (1912). Der Geburtenrückgang. Die Rationalisierung des Sexuallebens in unserer Zeit. Iena, G. Fisher. 254 p. 


\title{
HERBERT SPENCER: THE UNRECOGNIZED FATHER OF THE THEORY OF DEMOGRAPHIC TRANSITION
}

\section{ANATOLY VISHNEVSKY}

\begin{abstract}
It is believed that the central idea of the theory of the demographic transition from an equilibrium of high to an equilibrium of low mortality and fertility was formed and became generally recognized in the middle of the twentieth century. The article shows that this idea was developed by Herbert Spencer a hundred years before, although modern demographic transition theorists never refer to him as their predecessor. The main task of the article is to bring Spencer's arguments to the current debate about the present and the future of fertility, based on the premise that these arguments are not only not outdated, but are even today largely ahead of their time. The article does not deny Spencer's misconceptions about the mechanism of fertility decline in human society, but as to the causes of this decline, the higher level of generalization inherent in Spencer's scientific worldview predetermined an understanding of these causes deeper than that developed by modern theoretical demographers.
\end{abstract}

Key words: Spencer, demographic transition, mortality, fertility, ability to maintain life, ability to multiply, antagonism of reproduction and individualization, law of maintenance of species, equilibrium, causes of fertility decline, pro-natalist policy.

ANATOly G. Vishnevsky (avishnevsky@hse.ru), NATIONAL RESEARCH UnIVERSity Higher SCHOOL OF ECONOMICS, RUSSIA.

THE STUDY CARRIED OUT WITHIN THE FRAMEWORK OF THE BASIC RESEARCH PROGRAMME AT THE NATIONAL RESEARCH UNIVERSITY HIGHER SCHOOL OF ECONOMICS (HSE) IN 2017- 2018.

DATE RECEIVED : FEBRUARY 2019.

\section{REFERENCES}

Antonov A., Borisov V. (2011). Lekcii po demografii. Uchebnik dlja vuzov [Lectures on demography. University textbook]. Moscow: Academicheskiy prospect; Alma Mater. 584 p.

Bezanson A. (1922). The early use of the term Industrial Revolution. The Quarterly Journal of Economics, 36 (2), 343-349.

Brinton C. (1933). English Political Thought in the Nineteenth Century. London : Ernest Benn Limited.

Chesnais J.-C. (1986). La transition démographique. Etapes, formes, implications économiques. Etude de séries temporelles (1720-1984) relatives à 67 pays. INED. Travaux et documents. Cahier no 113. PUF. 580 p.

Caldwell J., Schindlmayr T. (2006). Explanations of the fertility crisis in modern societies: A search for commonalities. In Caldwell J. (Ed.), Demographic Transition Theory (pp. 349386). Springer,

Caldwell J.C. (1976). Toward a restatement of demographic transition theory. Population and Development Review, 2(3-4), 321-366.

Davis K. (1945). The World demographic transition. The Annals of the American Academy of Political and Social science. Vol. 237. World Population in Transition: 1-11 
Davis K. (1963). The theory of change and response in modern demographic history. Population Index. 29 (4), 345-366

Davis K. (1986). Low fertility in evolutionary perspective. Population and Development Review, Vol. 12, Supplement: Below-replacement fertility in industrial societies: Causes, consequences, policies, 48-65.

Davis K. (1997). Reproductive institutions and the pressure for population. Population and Development Review, 23(3), 611-624.

Encyclopedia of Sociology (2018). Family Size. Encyclopedia.com. 19 Aug. http://www.encyclopedia.com.

Hodgson D. (1983). Demography as social science and policy science. Population and Development Review, 9 (1), 1-34.

Kirk D. (1996). Demographic transition theory. Population Studies, 50 (3), 361-387.

Landry A. (1909). Les trois théories principales de la population. Scientia.

Landry A. (1933). La révolution démographique. Economic Essays in Honour of Gustav Cassel. October 1933. Frank Cass and Company Limited 1967, 357-368. English translation (1987): Adolphe Landry on the Demographic Revolution: Population and Development Review, 13(4), 731-740.

Landry A. (1934). La révolution démographique. Paris: Recueil Sirey.

Landry A. (1982). La révolution démographique. Études et essais sur les problèmes de la population. Paris: INED.

Levine H. et al. (2017). Temporal trends in sperm count: a systematic review and metaregression analysis. Human Reproduction Update, 23(6), 646-659.

Malthus T.R. (1998). An Essay on the Principle of Population [London 1798]. Electronic Scholarly Publishing Project. URL:

http://www.esp.org/books/malthus/population/malthus.pdf

Montesquieu Ch. (1995). De l'esprit des lois. Paris: Gallimard.

Nitti F. (1894). Population and the social system. London: Sansonnenschein \& Co.

Notestein F.W. (1945). Population - the long view. In T. Schultz (Ed.), Food for the World (pp. 37-57). Chicago: University of Chicago Press, 1945.

Parsons T. (1949). The Structure of Social Action. A Study of Social Theory with Special Reference to a Group of Recent European Writers. The Free Press. Glencoe, Illinois. 817 p.

Spencer H. (1852). A Theory of population, deduced from the general law of animal fertility. The Westminster Review, 57 [New Series, I(II)], 468-501.

Spencer H. (1891a). The nebular hypothesis. Essays: scientific, political, \& speculative. Vol. 1. URL: http://www.g,utenberg.org/files/29869/29869-h/29869-h.htm

Spencer H. (1891b). The Principles of Biology. Vol. 2. New York: D. Appleton and Company.

Spencer H. (1898). The Principles of Sociology, vol. 1 New York: D. Appleton and Company.

Spencer H. (1910). The Principles of Biology. Revised and enlarged edition. New York: D. Appleton.

Süssmilch J.P. (1998). L'Ordre divine. Paris, INED. 
Turner B.S. (1991). Preface to the new edition. In Parsons T. (Ed.), The Social System. Routledge.

Turner J.H. (1981) The forgotten theoretical giant: Herbert Spencer's models and principles. Revue européenne des sciences sociales, 19(59), 79-98.

van de Kaa D.J. (1987). Europe's Second Demographic Transition. Population Bulletin. 42(1). $57 \mathrm{p}$.

van de Kaa D. J. (1996). Anchored narratives: The story and findings of half a century of research into the determinants of fertility. Population Studies, 50 (3), 389-432.

van de Kaa D. J. (2010). Demographic transitions. In By Zeng Yi (Ed.), Encyclopedia of Life Support Systems (EOLSS). Demography, Vol. 1 (pp. 65-103). Oxford, UK: EOLSS Publishers.

Vilquin É. (2006). Histoire de la pensée démographique jusqu'en 1940. Démographie. Analyse et synthèse. Sous la direction de G. Caselli, J. Vallin et G. Wunsch. Vol. 7, Chapitre 97, 11-54. Paris, INED.

Vishnevsky A. (2014). The demographic revolution is changing the reproductive strategy of Homo sapiens. Demographic Review, English selection: 3-24. URL:

https://demreview.hse.ru/article/view/3155/2739

Wolf J. (1912). Der Geburtenrückgang. Die Rationalisierung des Sexuallebens in unserer Zeit. Iena, G. Fisher. 254 p. 